\title{
PERSEPSI PENGUNJUNG MENGENAI DAYA TARIK DAN HARAPAN TERHADAP KAWASAN BRAGA, BANDUNG
}

\author{
Levana Salsabila ${ }^{1}$, Hanson E. Kusuma ${ }^{2}$, Bakri Prakarso A. W. ${ }^{3}$ \\ 1. Program Studi Magister Rancang Kota, SAPPK, Institut Teknologi Bandung, \\ Jalan Ganesha Nomor 10, Bandung \\ 2. Kelompok Keahlian Perancangan Arsitektur, SAPPK, Institut Teknologi Bandung, Jalan \\ Ganesha Nomor 10, Bandung \\ 3. Asisten Akademik, SAPPK, Institut Teknologi Bandung, Jalan Ganesha Nomor 10, Bandung \\ Email: levanasalsabila@gmail.com
}

\begin{abstract}
Abstrak
Bandung sebagai kota destinasi wisata memiliki daya tarik yang beragam mulai dari wisata alam hingga wisata cagar budaya. Salah satu kawasan yang dijadikan tempat wisata cagar budaya di Bandung adalah kawasan Braga. Bangunan bersejarah di kawasan ini dapat dikenali dari langgam arsitektur art deco pada fasad bangunannya. Seiring dengan berjalannya waktu, Kota Bandung berkembang dan diikuti dengan kemunculan bangunan baru di beberapa kawasan termasuk kawasan Braga. Penelitian ini bertujuan untuk mengidentifikasi daya tarik dan harapan terhadap kawasan Braga menurut persepsi pengunjung. Metode penelitian yang digunakan adalah metode kualitatif dengan pengumpulan data menggunakan survei dalam bentuk kuesioner online yang dibagikan secara bebas (snowball-non-random sampling), sedangkan metode analisis data yang digunakan adalah analisis isi. Hasil penelitian mengungkapkan bahwa terdapat tiga pola persepsi antara daya tarik dan harapan terhadap kawasan Braga, yaitu Braga sebagai kawasan cagar budaya, kawasan hiburan, dan jalur sirkulasi.
\end{abstract}

Kata kunci: daya tarik, harapan, kawasan Braga, persepsi.

\begin{abstract}
Title: Visitor Perception about Attraction and Expectation of Braga Area, Bandung

Bandung as a popular city for travelers has a variety of attractions, ranging from natural to cultural heritage tourism. One of the areas that designated as cultural heritage attractions in Bandung is the Braga area. Historical buildings in this area can be recognized by the art deco architectural style on the facade of the building. As time goes by, the city of Bandung start to develop, followed by the appearance of new buildings in several regions including the Braga area. This study aims to identify the attractiveness and expectations of the Braga area according to visitors' perceptions. The research used qualitative method by collecting data using surveys in the form of online questionnaires that were distributed freely (snowball-non-random sampling), while the data analysis used content analysis. The results of the study revealed that there were three patterns of perception between attraction and expectation of the Braga region, namely Braga as a cultural heritage area, entertainment area, and circulation pathways.
\end{abstract}

Keywords: attraction, Braga area, expectation, perception.

\section{Pendahuluan}

Kawasan Braga yang merupakan destinasi wisata cagar budaya di Bandung, hingga kini masih ramai oleh pengunjung. Bangunan bersejarah di kawasan ini menjadi daya tarik tersendiri bagi para pengunjung. Beberapa bangunan yang masih mempertahankan bentuk aslinya menjadi tempat usaha, sebagian masih terawat, dan sebagian lainnya terabaikan (Sudaryanti, Sukriah, \& Rosita, 2015). Suasana tempo dulu 
begitu kental di kawasan ini sehingga para pengunjung sering menjadikan kawasan Braga sebagai tempat untuk berfoto-foto sembari menggali sejarah tentang kawasan ini.

Seiring dengan berjalannya waktu, Kota Bandung berkembang dan diikuti dengan kemunculan bangunanbangunan baru di beberapa kawasan termasuk kawasan Braga. Bangunanbangunan baru yang bermunculan ini umumnya lebih modern dan berwarna. Hal ini mengakibatkan adanya perubahan suasana di kawasan Braga yang sudah tampak berbeda dengan Braga terdahulu, kehadiran bangunan baru menjadi kontras dengan bangunan yang sudah lebih dulu berdiri di Braga. Perubahan yang terjadi menyebabkan memudarnya karakteristik bangunan yang tadinya merupakan satu kesatuan citra (Santoni, 2014). Kondisi ini tentu berdampak terhadap daya tarik kawasan Braga sebagai destinasi wisata cagar budaya, yang mana ratarata wisatawan tertarik mengunjungi Braga karena citra Braga sebagai kawasan cagar budaya dengan suasana kolonial dan mengharapkan agar bangunan-bangunan bersejarah di Braga tetap dipertahankan.

Kualitas daya tarik wisata merupakan faktor kunci yang paling menentukan minat wisatawan untuk mengunjungi destinasi (Basiya \& Rozak, 2012). Oleh karena itu, kualitas daya tarik wisata menjadi hal yang paling penting guna mendapatkan persepsi positif dari pengunjung (Nieamah, 2014). Program revitalisasi kawasan Braga yang dicanangkan pemerintah kota Bandung dengan menyelenggarakan festival seperti Braga Culinary Festival dan Braga Festival sejauh ini mampu mendatangkan pengunjung yang cukup banyak, akan tetapi masih belum dapat mengembalikan daya tarik Braga seperti dahulu (Sudaryanti et al., 2015).

Dalam Undang-Undang No. 10 Tahun 2009 disebutkan bahwa wisata adalah kegiatan perjalanan yang dilakukan oleh seseorang atau sekelompok orang dengan mengunjungi tempat tertentu untuk tujuan rekreasi, pengembangan pribadi, atau mempelajari keunikan daya tarik wisata yang dikunjungi dalam jangka waktu sementara. Keputusan perjalanan wisata harus dilihat secara menyeluruh berdasarkan motivasi, keinginan, kebutuhan dan pengharapan wisatawan secara personal atau sosial (Ismayanti, 2010).

Identitas Braga sebagai kawasan bersejarah mulai pudar. Secara normatif, identitas kawasan bersejarah Braga seharusnya dipertahankan, tetapi pengembangan kawasan Braga tidak akan lepas dari persepsi semua pemangku kepentingan, termasuk di dalamnya pengunjung. Penelitian ini menggali persepsi pengunjung, yang kebutuhannya cenderung diwadahi oleh pemangku kepentingan yang terlibat secara langsung dalam pengembang kawasan Braga.

Berkaitan dengan hal tersebut, penelitian terhadap kawasan Braga ini merupakan studi awal untuk mengidentifikasi daya tarik dan harapan kawasan Braga menurut persepsi pengunjung. Daya tarik dan harapan merupakan persoalan penting karena daya tarik akan mendorong pengunjung untuk datang (pull factor) (Prameswari, Ardhyanto, \& Kusuma, 2018) dan harapan digunakan untuk mengakomodasi kebutuhan pengunjung di masa depan. Penelitian ini diharapkan dapat mengeksplorasi kebutuhan di dalam perencanaan maupun perancangan program revitalisasi kawasan untuk meningkatkan daya tarik kawasan tanpa menghilangkan citra kawasan. 


\section{Metode Penelitian}

Metode yang digunakan dalam penelitian ini adalah metode penelitian kualitatif (Creswell, 2008) yang bersifat eksploratif (Groat \& Wang, 2002) untuk mendapatkan data berupa informasi mengenai daya tarik kawasan yang menarik minat kunjungan berdasarkan persepsi responden terhadap kawasan Braga.

\section{Metode Pengumpulan Data}

Pengumpulan data dilakukan dengan menggunakan survei dalam bentuk kuesioner online yang berisi pertanyaan bersifat terbuka (open ended). Kue-sioner online dibagikan secara bebas (snowball-non-random sampling), baik lewat media sosial ataupun lewat kenalan pribadi, dengan tujuan menggali lebih dalam persepsi responden terhadap daya tarik kawasan yang telah dikunjungi (Kumar, 2005). Pertanyaan dalam kuesioner online disusun secara kualitatif dan kuantitatif (mix-method). Pertanyaan kuantitatif dengan struktur pertanyaan tertutup (close-ended), sedangkan pertanyaan kualitatif menggunakan struktur pertanyaan terbuka (open-ended). Data yang digunakan dalam pembahasan ini adalah data teks yang bersifat kualitatif. Responden diminta untuk menuliskan persepsinya terhadap daya tarik kawasan yang menarik minat kunjungan mereka. Pertanyaan ini berbentuk pertanyaan terbuka (openended), sehingga responden dapat menuliskan isi pikiran mereka mengenai daya tarik kawasan dan harapan mereka terhadap kawasan Braga sesuai dengan pengalaman masing-masing.

Kuesioner mulai dibagikan pada tanggal 2 September 2018 dan ditutup pada 6 September 2018. Jumlah responden yang mengisi 123 , dengan responden perempuan sebanyak 69 orang $(56,1 \%)$ dan laki-laki sebanyak 54 orang $(43,9 \%)$.

\section{Metode Analisis Data}

Metode analisis data yang digunakan dalam penelitian adalah analisis isi, analisis distribusi, dan analisis korespondensi. Analisis isi terdiri dari 3 tahap yaitu open coding, axial coding, dan selective coding (Creswell, 1998).

Tahap open coding merupakan tahap identifikasi kata kunci dari setiap pernyataan responden mengenai daya tarik kawasan Braga, kegiatan selama berada di kawasan dan harapan responden terhadap kawasan. Pada tahap ini juga kata-kata kunci yang mirip dikelompokkan menjadi kategori. Kategori yang diperoleh dianalisis dengan analisis distribusi. Analisis distribusi dilakukan dengan melihat perbandingan frekuensi masing-masing kategori sehingga didapatkan faktor yang dominan dan tidak dominan.

Selanjutnya dilakukan tahapan axial coding, yaitu dengan mengungkap hubungan antar kategori. Pada tahap ini digunakan metode analisis korespondensi, yang merupakan analisis kuantitatif yang berfungsi mengungkap coincidence/concurrence antar kategori. Tahap terakhir selective coding. Pada tahap ini, hasil open coding dan axial coding digunakan untuk merumuskan model hipotesis yang menjelaskan hubungan antar kategori daya tarik dan harapan responden terhadap kawasan Braga yang merupakan abstraksi temuan.

\section{Hasil dan Pembahasan}

Tahap analisis isi pertama open coding. Tahap ini dilakukan dengan membedah jawaban responden yang berupa data teks dengan menemukan kata-kata kunci yang mewakili unit makna yang disampaikan responden. 
Berikut contoh data teks dan proses open coding dari jawaban beberapa responden mengenai daya tarik kawasan Braga.

"Citra kawasan braga yang khas dan mempunyai nilai estetik dan autentik tersendiri." (Mahasiswa)

"Deretan bangunan lama dengan gaya arsitektur kolonial dan art deco, tokotoko jadul yang menjual makanan enak." (Pekerja)

"Suasana zaman dulu yang menarik, ditambah ada kuliner yang enak juga buat dikunjungi disana." (Pekerja)

Dari jawaban-jawaban responden di atas dapat diambil kata kunci seperti "citra kawasan", "estetika", "bangunan kolonial", "tampilan bangunan", "toko", "suasana", dan "makanan".

Teks dan open coding dari jawaban responden mengenai harapan untuk kawasan Braga dapat dilihat pada contoh kutipan di bawah ini.

"Saya harap ada perhatian khusus untuk perawatan bangunan-bangunan di Braga, agar dapat membawa pengunjung ke suasana khas yang hanya bisa didapatkan di kawasan Braga. Bangunan-bangunan yang kosong dan kumuh diperbaiki dan difungsikan kembali agar dapat benarbenar hidup di siang hari mengimbangi suasana pada malam hari." (Pekerja) "Lebih ramah pejalan kaki dan lebih memiliki fasilitas publik." (Mahasiswi)

Berdasarkan kutipan jawaban-jawaban responden di atas, dapat diambil kata kunci seperti "perawatan bangunan", "perbaikan bangunan", "difungsikan kembali", "menjaga suasana", "ramah pejalan kaki", dan "memiliki fasilitas".
Tabel 1. Contoh kategori dari daya tarik

\begin{tabular}{|c|c|c|}
\hline No & $\begin{array}{l}\text { Kategori } \\
\text { anak }\end{array}$ & Kata kunci \\
\hline \multirow{7}{*}{1} & \multirow{7}{*}{$\begin{array}{l}\text { Elemen } \\
\text { pembentuk } \\
\text { kota }\end{array}$} & Perabotan jalan \\
\hline & & Material jalan \\
\hline & & Jalan \\
\hline & & Tata ruang \\
\hline & & Jalur pedestrian \\
\hline & & Desain kawasan \\
\hline & & Citra kawasan \\
\hline \multirow{6}{*}{2} & \multirow{6}{*}{$\begin{array}{l}\text { Tipologi } \\
\text { bangunan }\end{array}$} & Bangunan kolonial \\
\hline & & Fasad bangunan \\
\hline & & Bentuk bangunan \\
\hline & & Fungsi bangunan \\
\hline & & Tampilan bangunan \\
\hline & & Bangunan oriental \\
\hline
\end{tabular}

Sumber: Hasil analisis, 2018

Tabel 2. Contoh kategori dari harapan terhadap kawasan Braga

\begin{tabular}{|c|c|c|}
\hline No & $\begin{array}{l}\text { Kategori } \\
\text { anak }\end{array}$ & Kata kunci \\
\hline \multirow{7}{*}{1} & \multirow{7}{*}{$\begin{array}{l}\text { Meningkatkan } \\
\text { kegiatan }\end{array}$} & Difungsikan kembali \\
\hline & & Ada festival \\
\hline & & Perbanyak toko \\
\hline & & $\begin{array}{l}\text { Optimalisasi shared } \\
\text { street }\end{array}$ \\
\hline & & Lebih ramai \\
\hline & & $\begin{array}{l}\text { Pengembangan bisnis } \\
\text { komersial }\end{array}$ \\
\hline & & Tempat kuliner \\
\hline \multirow{3}{*}{2} & \multirow{3}{*}{$\begin{array}{l}\text { Pemeliharaan } \\
\text { bangunan }\end{array}$} & Perawatan bangunan \\
\hline & & Perbaikan bangunan \\
\hline & & Warna bangunan \\
\hline
\end{tabular}

Sumber: Hasil analisis, 2018

Selanjutnya kata-kata kunci yang mirip dikelompokkan menjadi kategori. Penyusunan kategori dilakukan dengan tinjauan literatur dari jurnal-jurnal yang sudah dipublikasi sebelumnya dan dengan diskusi kelompok belajar untuk menghindari adanya kesamaan ataupun bias. Ditemukan 7 kategori anak pada daya tarik dan 11 kategori anak pada harapan. Berikut contoh penyusunan kategori dari open coding daya tarik pada Tabel 1 dan harapan pada Tabel 2 .

Dari hasil open coding didapatkan 7 kategori anak pada daya tarik, yaitu elemen pembentuk kota, tipologi 
bangunan, wisata kuliner, suasana kawasan, kegiatan jalan kaki, kegiatan hobi, dan bersosial. Penentuan kategori ini didasarkan pada daya tarik wisata cagar budaya atau cultural heritage tourism yang terdiri dari archaeological historical and cultural sites, distinctive cultural patterns, arts and handicrafts, interesting economic activities, interesting urban areas, museum and other cultural facilities, dan cultural festivals (Liyushiana \& Sianipar, 2017).

Kategori tipologi bangunan berkaitan dengan daya tarik archaeological historical and cultural sites, yang meliputi peninggalan dan situs sejarah maupun budaya berupa bangunan bersejarah atau bangunan-bangunan yang digunakan untuk event atau kegiatan bersejarah. Sementara untuk kategori suasana kawasan berkaitan dengan daya tarik interesting urban areas yakni daya tarik berupa kondisi area perkotaan yang terdiri atas gaya arsitektural bangunan dan keberadaan daerah-daerah bersejarah. Kondisi bangunan merupakan objek utama yang mendasari daya tarik wisata berbasis sejarah budaya karena keunikan bangunan dan bentuk fisiknya menjadi identifikasi yang sekaligus membedakan dengan daerah tujuan wisata lainnya (Bullen \& Love, 2011).

Pada kategori harapan diperoleh 11 kategori anak, yang terdiri dari tidak mengubah bangunan, sirkulasi lancar, pemeliharaan bangunan, meningkatkan kegiatan, menghidupkan kawasan, kondisi terjaga, keteraturan tempat parkir, kenyamanan pedestrian, kawasan teratur, kawasan bebas kendaraan, dan fasilitas publik memadai.

Setelah kategori ditentukan, selanjutnya analisis distribusi. Analisis distribusi ini dilakukan dengan melihat frekuensi dari jawaban responden sehingga didapat jawaban responden yang dominan muncul atau sebaliknya.

Selain melihat daya tarik dan harapan pengunjung terhadap kawasan Braga, dilakukan juga pemetaan jenis kegiatan yang sering dilakukan oleh pengunjung ketika mendatangi kawasan ini yang dapat dilihat pada gambar 1 .

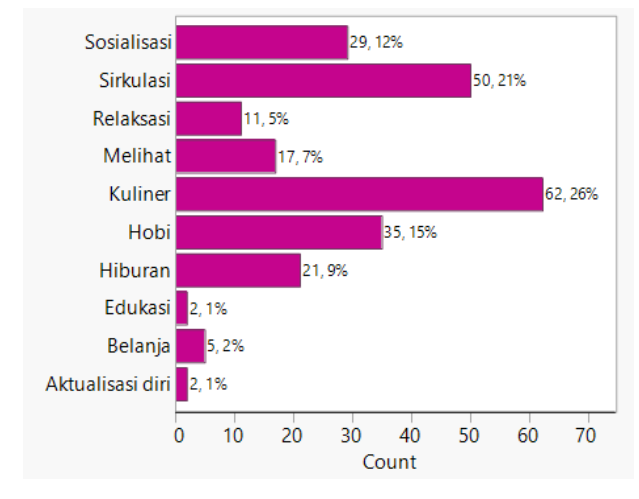

Gambar 1. Analisis distribusi kegiatan di kawasan Braga

Sumber: Hasil analisis, 2018

Terlihat bahwa kegiatan yang paling sering dilakukan oleh pengunjung adalah kegiatan kuliner dengan presentase $62,26 \%$ (f: 62), kemudian kegiatan sirkulasi/berjalan-jalan sebesar 50,21\% (f: 50). Kegiatan edukasi dan kegiatan aktualisasi diri menempati posisi terendah dengan 2,1\% (f: 2 ).

Sebagai salah satu kawasan wisata yang berada di pusat kota Bandung, tidak mengherankan jika kegiatan yang paling digemari adalah kegiatan kuliner. Restoran dan kafe tempo dulu yang masih berdiri hingga saat ini seperti restoran Braga Permai Maison Bogerijen yang menyajikan makanan khas Eropa (Gambar 2), lalu toko roti Sumber Hidangan dengan sajian berbagai jenis roti dan kue juga es krim, menjadi tujuan para pecinta kuliner yang berkunjung ke Braga. Munculnya kafe-kafe baru yang menempati bangunan kolonial di Braga seperti Wiki Koffie berhasil menjaring 
banyak anak muda setiap harinya (Gambar 3). Kehadiran restoran dan kafe ini harus dipertahankan dan dikembangkan sehingga ke depannya dapat terus meningkatkan kegiatan perdagangan barang dan jasa.

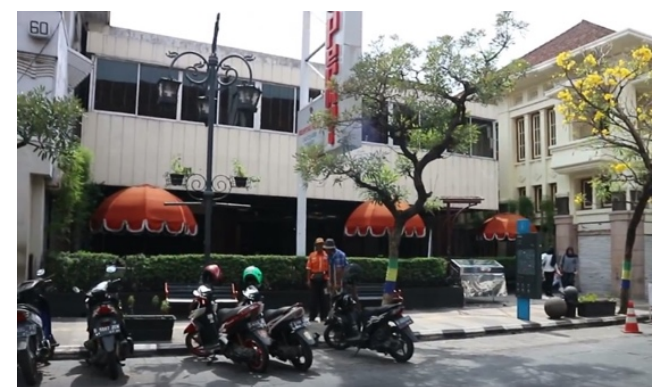

Gambar 2. Restoran Braga Permai Sumber: Dokumentasi Salsabila, 2018

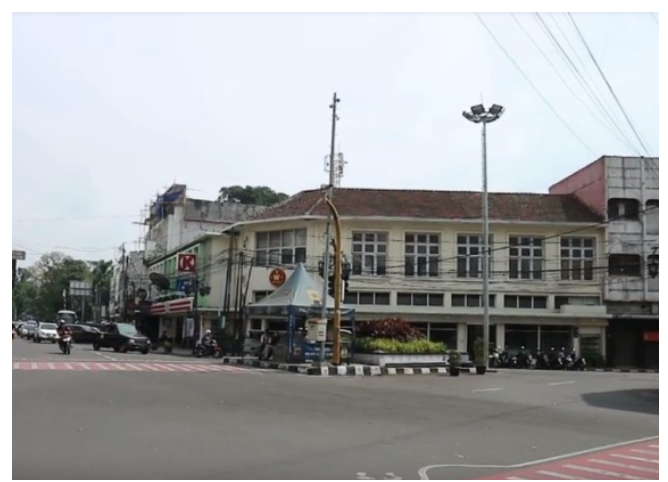

Gambar 3. Kafe Wikie Koffie

Sumber: Dokumentasi Salsabila, 2018

Kegiatan yang juga banyak dilakukan di kawasan Braga adalah kegiatan sirkulasi yang utamanya ialah sirkulasi pejalan kaki. Banyak pengunjung yang menikmati suasana Braga sambil berjalan kaki, karena Jalan Braga dinilai cukup nyaman dan bersih (Gambar 4). Walaupun cukup nyaman, kondisi pedestrian way di kawasan ini belum sepenuhnya baik, beberapa batu andesit sebagai material pedestrian way mulai tidak beraturan di beberapa titik. Pemkot Bandung diharapkan dapat menjadikan kawasan Braga sebagai kawasan khusus pejalan kaki dan tidak lagi dilintasi kendaraan agar kawasan ini menjadi kawasan yang nyaman dan aman untuk pejalan kaki.

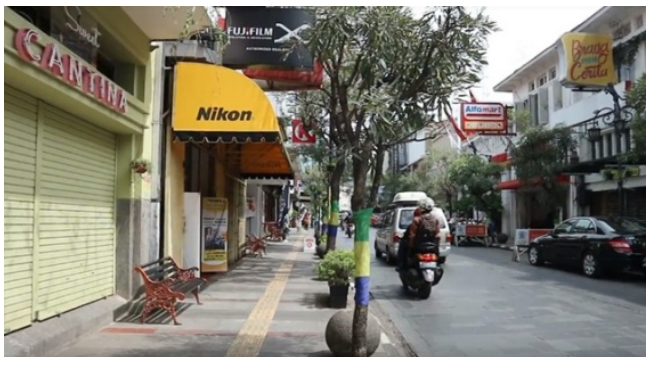

Gambar 4. Jalur pedestrian dan sirkulasi kendaraan kawasan Braga

Sumber: Dokumentasi Salsabila, 2018

Pada gambar 5 dapat dilihat analisis distribusi daya tarik di kawasan Braga. Tipologi bangunan menjadi daya tarik yang paling dominan dengan presentase sebesar $52,30 \%$ (f: 52), diikuti oleh daya tarik berupa suasana kawasan yaitu 43,25\% (f: 43) dan elemen pembentuk kota dengan presentase $32,18 \%$ (f: 32). Hasil analisis distribusi pada daya tarik di kawasan Braga menunjukkan bahwa tipologi bangunan yang berupa bangunan-bangunan kolonial merupakan daya tarik yang paling berpengaruh terhadap motivasi kunjungan pengunjung.

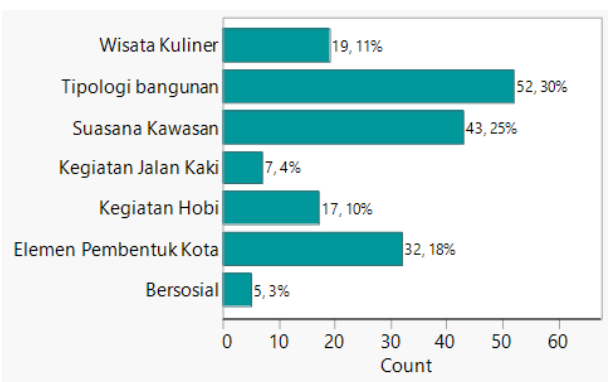

Gambar 5. Analisis distribusi daya tarik di kawasan Braga

Sumber: Hasil analisis, 2018

Beberapa bangunan cagar budaya di kawasan Braga seperti gedung Landmark, gedung AACC (New Majestic), dan Hotel Bidakara Savoy Homann merupakan daya tarik tersendiri bagi para pengunjung karena arsitektur bangunannya yang menyerupai bangunan di Eropa (Gambar 6) Tak jarang bangunan-bangunan cagar 
budaya ini dijadikan sebagai objek atau latar foto oleh pengunjung ketika mereka berada di kawasan Braga.

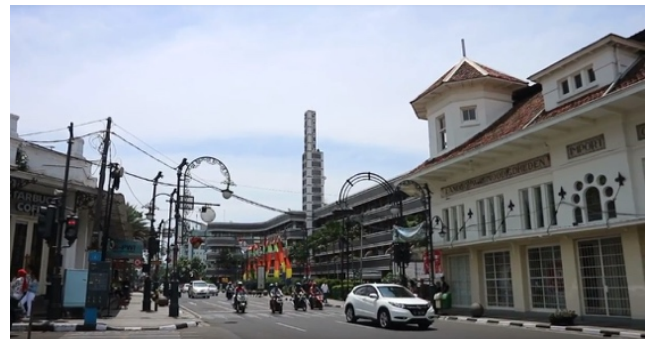

Gambar 6. Hotel Bidakara Savoy Homann Sumber: Dokumentasi Salsabila, 2018

Daya tarik selanjutnya adalah suasana kawasan yang merepresentasikan suasana, estetika, dan kebersihan, serta menjadi alasan yang mendukung daya tarik kawasan Braga. Sementara kegiatan seperti jalan kaki dan bersosial tidak memberikan pengaruh terhadap daya tarik kawasan.

Dari hasil analisis distribusi harapan di kawasan Braga diperlihatkan pada Gambar 7. Terlihat kecenderungan bahwa harapan pengunjung yang paling banyak adalah kawasan teratur $31,17 \%$ (f: 31 ), disusul dengan pemeliharaan bangunan $22,12 \%$ (f: 22), lalu dilanjutkan dengan tidak mengubah bangunan 21,12\% (f: 21 ).

Analisis distribusi harapan di kawasan Braga menunjukkan bahwa pengunjung sangat menginginkan kawasan Braga menjadi kawasan yang teratur dan rapi, serta diharapkan juga adanya pemeliharaan bangunan-bangunan bersejarah di kawasan Braga agar kawasan ini tidak kehilangan daya tariknya (lihat gambar 7).

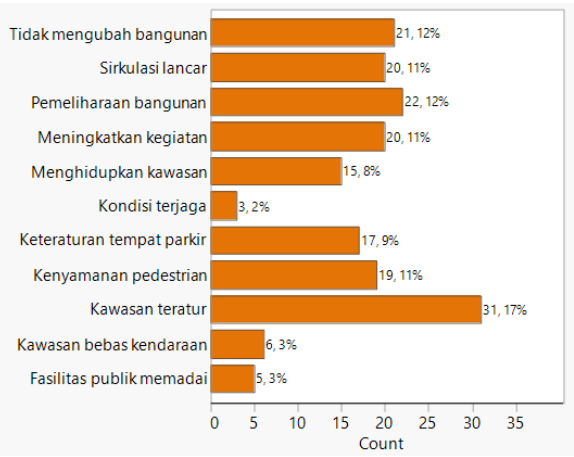

Gambar 7. Analisis distribusi harapan di kawasan Braga

Sumber: Hasil analisis, 2018

Selanjutnya, analisis yang dilakukan adalah axial coding dengan analisis korespondensi, yang bertujuan untuk mengetahui coincidence antara daya tarik kawasan Braga dengan harapan pengunjung. Penerapan analisis korespondensi ini dilakukan dengan cara cluster analysis menggunakan ward hierarchical cluster. Nilai signifikansi dari analisis korespondensi sebesar $p=0.2866(29 \%)$ yang berarti ketepatan prediksi hubungan antara daya tarik dengan harapan pengunjung sebesar 0.7134 (71\%). Hasil analisis dapat dilihat di Dendrogram pada Gambar 8. Pada Dendrogram, semakin dekat posisi cabang, semakin tinggi korespondensi antar kategori.

Dapat dilihat bahwa responden yang merasakan daya tarik kawasan Braga berdasarkan elemen pembentuk kota seperti desain dan citra kawasan, perabotan dan material jalan memiliki harapan yang sama dengan responden yang memiliki daya tarik terhadap tipologi bangunan kawasan seperti bangunan kolonial, fasad, bentuk, fungsi, serta tampilan bangunan, yaitu berharap agar ada pemeliharaan bangunan dan tidak mengubah bangunan yang ada di kawasan Braga. Hal tersebut berkaitan dengan kegiatan sosial responden yang berharap kegiatan di kawasan ini ditingkatkan. 


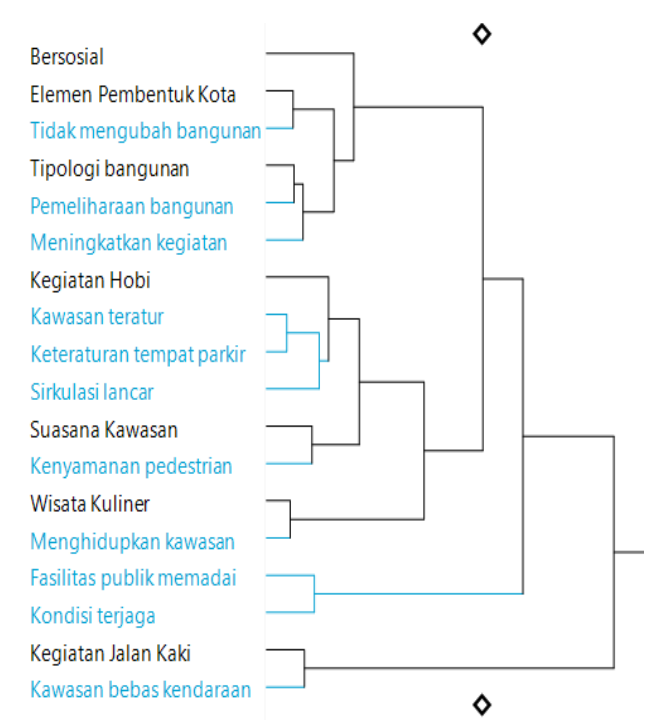

Gambar 8. Dendrogram hasil analisis korespondensi antara daya tarik dan harapan di kawasan Braga Sumber: Hasil analisis, 2018

Responden yang berpendapat bahwa kawasan Braga memiliki daya tarik pada kegiatan hobi seperti musik, lukisan, pakaian, sejarah dan spot foto maupun daya tarik terhadap wisata kuliner dan suasana kawasan mengharapkan kawasan Braga menjadi kawasan yang lebih teratur, baik dari keteraturan tempat parkir maupun sirkulasi kendaraan dan pejalan kaki, lalu kawasan yang lebih hidup, dan juga memberikan kenyamanan yang lebih bagi pejalan kaki. Sedangkan bagi responden yang tertarik dengan kegiatan berjalan kaki di kawasan Braga, mengharapkan agar kawasan Braga menjadi kawasan yang bebas kendaraan atau berorientasi terhadap pejalan kaki.

Terdapat satu pengelompokan harapan yang tidak berkaitan langsung terhadap daya tarik, yaitu fasilitas publik memadai dan kondisi terjaga, namun hal tersebut berdekatan dengan daya tarik suasana kawasan, bersosial, hobi, wisata kuliner, elemen pembentuk kota, dan tipologi bangunan. Kedua harapan ini dapat mewakili berbagai daya tarik tersebut.
Setelah axial coding, selanjutnya dilakukan selective coding berdasarkan pola korespondensi antara daya tarik dan harapan terhadap kawasan Braga yang diperlihatkan pada Dendrogram gambar 8. Dari pola korespondensi tersebut terungkap tiga klaster persepsi terhadap kawasan Braga (lihat gambar 9). Yang pertama, persepsi Braga sebagai kawasan cagar budaya. Yang ke-dua, persepsi Braga sebagai kawasan hiburan. Yang ke-tiga, persepsi Braga sebagai jalur sirkulasi.

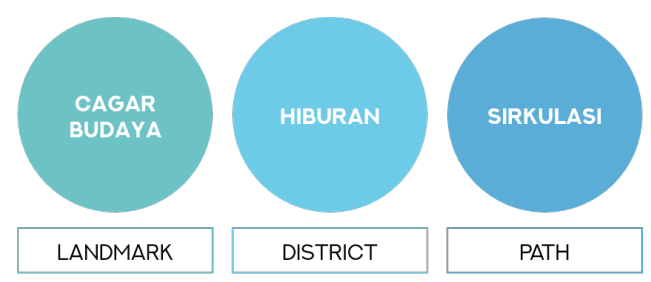

Gambar 9. Tiga persepsi terhadap kawasan Braga (model hipotesis) Sumber: Hasil analisis, 2018

Pengunjung yang memiliki persepsi sebagai kawasan cagar budaya cenderung melihat Braga sebagai kawasan yang menjadi landmark (Lynch, 1960) kota Bandung. Bangunan-bangunan bersejarah yang berada di Braga merupakan identitas yang membedakan Braga dengan kawasan lainnya. Pada skala kota, Braga dianggap sebagai satu titik yang ditandai oleh tipologi bangunan kolonial dan elemen-elemen pembentuk kota yang khas. Persepsi Braga sebagai kawasan cagar budaya mendorong harapan konservasi terhadap kawasan Braga (Sudaryanti et al., 2015).

Persepsi yang ke-dua, kawasan Braga dipahami sebagai kawasan hiburan. Pengunjung datang ke Braga untuk makan-makan, berfoto, atau melakukan kegiatan hobi lainnya. Kegiatan-kegiatan tersebut dilakukan di banyak titik di kawasan Braga. Kawasan Braga dipersepsi sebagai district yang dapat mewadahi beragam 
kegiatan hiburan yang menyenangkan dan menjadi destinasi yang menarik bagi wisatawan di kota Bandung (Basiya \& Rozak, 2012).

Persepsi kelompok yang ke-tiga, melihat Braga sebagai kawasan pedestrian dan jalur sirkulasi. Pedestrian berjalan kaki di Braga untuk menikmati suasana ataupun untuk mencapai tempat tujuan. Posisi jalan Braga secara hirarki merupakan jalur penghubung utama (path) dari kawasan di sebelah selatan dan utara Braga, sehingga Braga sebagai jalur sirkulasi membentuk persepsi penggunanya.

\section{Kesimpulan}

Kawasan Braga memiliki daya tarik yang berdampak positif bagi perkembangan wisata cagar budaya di Bandung. Menurut persepsi pengunjung tipologi bangunan bersejarah merupakan daya tarik paling dominan dari kawasan Braga. Karena itu keberadaan bangunan-bangunan bersejarah tersebut diharapkan agar terus dipertahankan. Pengunjung juga berharap kawasan Braga menjadi teratur. Keteraturan kawasan Braga akan meningkatkan kenyamanan pengunjung dan citra Braga sebagai kawasan cagar budaya.

Berdasarkan hasil analisis, untuk mempertahankan identitas Braga sebagai kawasan bersejarah, pengembangan kawasan Braga seharusnya bertumpu pada tiga pola persepsi (Gambar 9). Braga secara simultan dikembangkan sebagai kawasan cagar budaya, kawasan hiburan, dan juga jalur sirkulasi.

Dari penelitian ini dapat direkomendasikan bahwa diperlukan pemahaman terhadap persepsi pengunjung dalam perencanaan pengembangan kawasan Braga. Tingkat signifikansi pada penelitian ini masih rendah. Karena itu pada penelitian selanjutnya disarankan menambah jumlah responden untuk meningkatkan keandalan (reliability) hasil penelitian.

\section{Daftar Pustaka}

Basiya, R., \& Rozak, H. A. (2012). Kualitas daya tarik wisata, kepuasan dan niat kunjungan kembali wisatawan mancanegara di Jawa Tengah. Jurnal Ilmiah Dinamika Kepariwisataan, 11, 1-12. Retrieved from https://www.unisbank.ac.id/ojs/inde x.php/pdk1/article/view/1715

Bullen, P. A., \& Love, P. E. D. (2011). Adaptive reuse of heritage buildings. Structural Survey. https://doi.org/10.1108/0263080111 1182439

Creswell, J. W. (1998). Qualitative inquiry and research design: Choosing among five tradition. London: SAGE Publications.

Creswell, J. W. (2008). Research design: Qualitative, quantitative, and mixed methods approaches (3rd ed.). Thousand Oaks, CA, US: Sage Publications, Inc.

Groat, L. N., \& Wang, D. (2002). Architectural research methods. New York: John Wiley and Sons Ltd.

Ismayanti. (2010). Pengantar pariwisata. Jakarta: Grasindo.

Kumar, R. (2005). Research methodology second edition. London: SAGE Publications.

Liyushiana, \& Sianipar, C. (2017). Pengelolaan koridor jalan Ahmad Yani sebagai daya tarik wisata pusaka. Jurnal Khasanah Ilmu, 8, 45-59. Retrieved from https://ejournal.bsi.ac.id/ejurnal/ind ex.php/khasanah/article/view/2409/ 1716

Lynch, K. (1960). The image of the city. Cambridge: MIT Press.

Nieamah, K. F. (2014). Persepsi wisatawan mancanegara terhadap fasilitas dan pelayanan di Candi Prambanan. Jurnal Nasional 
Pariwisata, 6, 39-45. Retrieved from

https://jurnal.ugm.ac.id/tourism_par iwisata/article/download/6875/5379

Prameswari, D. R., Ardhyanto, A., \&

Kusuma, H. E. (2018).

Korespondensi motivasi pengunjung dan karakteristik desa wisata. Jurnal Lingkungan Binaan Indonesia, 7(1), 24-31. Retrieved from https://jlbi.iplbi.or.id/korespondensi -motivasi-pengunjung-dankarakteristik-desa-wisata/

Santoni. (2014). Transformasi dan tipologi bangunan Indo-Europeeschen Architectuur Stijl kawasan Braga Bandung. E-Journal Graduate Unpar, 1, 162-177. Retrieved from http://journal.unpar.ac.id/index.php/ unpargraduate/article/view/1193/11 65

Sudaryanti, I. J., Sukriah, E., \& Rosita. (2015). Analisis faktor-faktor yang mempengaruhi motivasi wisatawan dalam melakukan wisata heritage di kawasan Braga kota Bandung. Jurnal Manajemen Resort \& Leisure, 12, 43-56. Retrieved from http://ejournal.upi.edu/index.php/jur el/article/view/1047/701 